\title{
POSSIBILIDADES DE CONTRIBUIÇÃO DA INFOGRAFIA COMO TECNOLOGIA ASSISTIVA EM BENEFÍCIO DO ACESSO À EDUCAÇÃO A PESSOAS COM TDAH
}

\author{
Luciano Adorno, MSc. \\ contato@lucianoadorno.com.br-UFSC, UNIVALI e IFSC \\ Bruna Reginato, Esp. \\ brunareginato@gmail.com - UFSC
}

Resumo: Muitos estudos na área de Tecnologia Assistiva tendem a abordar o uso de dispositivos tecnológicos, focando em produtos e seus recursos de interação e mediação. Estes estudos apresentam-se, geralmente, como análises ou sugestões de possibilidades de uso de tecnologia, a qual muitas vezes depende da disponibilidade ou do desenvolvimento de softwares ou de máquinas. Contudo, a tecnologia pode apresentar-se em forma de solução estratégica. Neste sentido, busca-se evidenciar a possibilidade de desenvolvimento de um modelo conceitual que auxilie na melhoria do acesso à educação para pessoas com TDAH, a partir do estudo da relação entre infografia, TA, educação e TDAH. Para isto, foi eleito o método "analítico-descritivo". Entre os resultados obtidos destacam-se: (A) a necessidade de ampliação das pesquisas na área; (B) o reforço da relevância da investigação do tema proposto; (C) a existência de ferramentas intuitivas e customizáveis para composição de infografias; (D) a possibilidade de melhoria no aprendizado a partir da infografia entre outros.

Palavras-chave: ensino, TDAH, design gráfico, infográfico, modelo conceitual.

Abstract: Many studies in the area of Assistive Technology tend to approach the use of technological devices, focusing on products and their features of interaction and mediation. These studies are presented, usually as reviews or suggestions for possible uses of technology, which often depends on the availability or development of software or machines. However, the technology can present itself in the form of strategic solution. In this sense, search itself to evidence the possibility of developing of a conceptual model that assists in improving access to education for people with $A D H D$, from the study of the relationship between infographic, TA, education and ADHD. To this end, the method chosen was "analytical-descriptive". Among the results are: $(A)$ the need for further research in the area, $(B)$ strengthening the relevance of the research proposed theme, (C) the existence of intuitive and customizable tools for composition infographics; (D) the possibility of improvement in learning from infographic and others.

Keywords: teaching, $A D H D$, graphic design, infographic, conceptual model. 


\section{INTRODUÇÃO}

A pesquisa exploratória a respeito do tema "tecnologia assistiva: acesso à educação", dentre o material analisado, indicou que os estudos na área tendem a abordar aspectos relacionados à ampliação de possibilidades do aprendizado da pessoa deficiente. Isto ocorre a partir do uso de dispositivos tecnológicos, focando em produtos e seus recursos de interação e mediação. Assim, estes tem por objetivo minimizar determinadas limitações do usuário.

Desta forma, é relevante considerar aqui que a adoção da tecnologia pela tecnologia não garante melhorias nos resultados de aprendizagem ou enriquecimento na experiência educacional (MURPHY, 2011).

A partir destas premissas, constatou-se ainda que estes estudos apresentam-se como análises ou sugestões de possibilidades de uso de tecnologia, a qual muitas vezes depende da disponibilidade ou do desenvolvimento de softwares ou de máquinas, o que torna grande parte destas sem uma aplicação efetiva em razão de motivos como custo elevado ou falta de habilidade para execução do projeto. Contudo, tem-se a consciência de que o projeto pode vir a ser subsidiado pelo Governo ou entidades privadas. E que o pesquisador não precisa dominar engenharia, por exemplo, para poder contribuir com a pesquisa na área. Todavia, a tecnologia pode manifestar-se de modo que não se configure necessariamente na construção de um produto. Pode apresentar-se em forma de solução estratégica como em uma proposta metodológica ou um modelo conceitual.

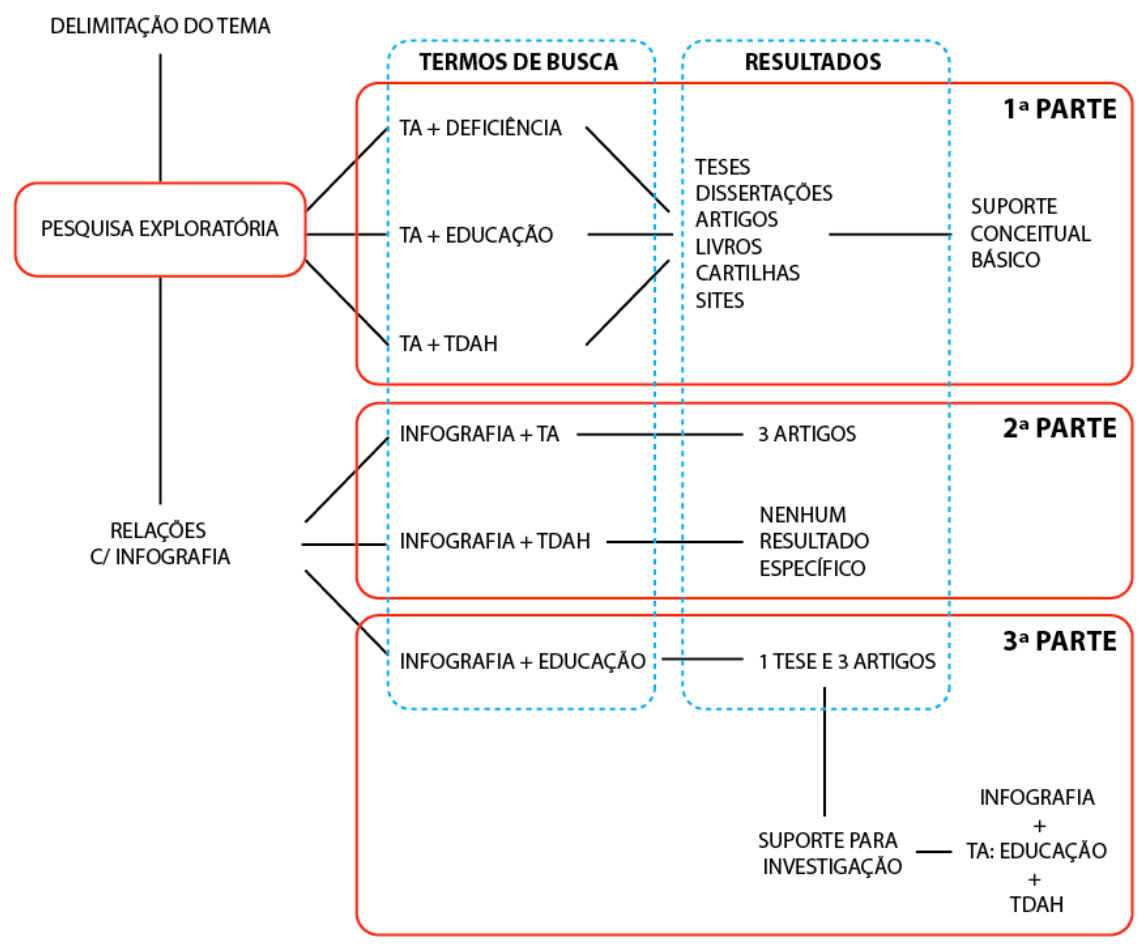

Figura 1: Pesquisa exploratória. Fonte: Elaborado pelos autores, com base na pesquisa realizada.

$\mathrm{Na}$ primeira parte da pesquisa exploratória buscou-se artigos que relacionassem os temas (1) "TA+deficiência", (2) "TA+educação" e (3) "TA+TDAH" (fig. 1) para construção do suporte conceitual básico da pesquisa, que tem por objetivo elucidar inicialmente os conceitos envolvidos neste estudo. 
Em um segundo momento, a partir da base de dados do Google Acadêmico, buscou-se investigar a existência de artigos que relacionavam TA ou TDAH à infografia (fig. 1). Em relação a busca de palavras-chave "infografia+TA" foram encontrados 3 artigos, sendo que um deles além de abordar sobre infografia e TA aborda sobre ensino (CARDOSO \& KOLTERMANN, 2010), apresentando-se como uma versão anterior de um dos artigos encontrados posteriormente pela busca "infografia+educação" (quadro 1).

Os outros dois artigos encontrados (quadro 1) a partir da busca sobre "infografia+TA" tratam de: $(A)$ infografias tridimensionais para o ensino de deficientes visuais (MILAN, 2008) e o segundo (B) não apresenta relação com o termo TA, mas é do interesse deste estudo, pois apresenta relação entre infografia e educação (PEÇAIBES \& MEDEIROS, 2010).

Em resumo, esta pesquisa exploratória apresenta 6 artigos e 1 tese, comportando apenas 2 artigos sobre a relação "infografia+TA" e 4 artigos e 1 tese sobre "infografia+educação", sendo que 1 artigo de cada tema possui relação com os 2 temas (TA e educação) pesquisados mais o tema infografia, conforme apresentado na última linha grifada do quadro a seguir .

Quadro 1 - Reorganização da relação identificada no material parcial da pesquisa exploratória

\begin{tabular}{|c|c|c|}
\hline Termo de busca & Material & Resultado por Autores \\
\hline Infografia+TA & $\begin{array}{l}2 \text { artigos } \\
\text { (artigo riscado, sem relação com o } \\
\text { termo de busca) }\end{array}$ & $\begin{array}{l}\text { MILAN, } 2008 \\
\text { CARDOSO \& KOLTERMANN, } 2010 \\
\text { PEÇAIBES\& MEDEIROS, } 2010\end{array}$ \\
\hline Infografia+TDAH & Nenhum & Nenhum \\
\hline Infografia+educação & $\begin{array}{l}4 \text { artigos e } 1 \text { tese } \\
\text { (sendo } 1 \text { dos artigos proveniente } \\
\text { de busca por outro tema) }\end{array}$ & $\begin{array}{l}\text { PEÇAIBES \& MEDEIROS, } 2010 \\
\text { STRACK et al, } 2011 \\
\text { BOTTENTUIT et al, } 2011 \\
\text { PESSOA \& MAIA, } 2012 \\
\text { ALVAREZ, } 2012\end{array}$ \\
\hline Infografia+educação+TA & $\begin{array}{l}2 \text { artigos } \\
\text { (sendo } 1 \text { artigo a continuidade do } \\
\text { outro e com autores em comum) }\end{array}$ & $\begin{array}{l}\text { CARDOSO \& KOLTERMANN, } 2010 \\
\text { STRACK et al, } 2011\end{array}$ \\
\hline
\end{tabular}

Fonte: Elaborado pelos autores, com base na pesquisa realizada.

Portanto, analisando-se a tabela, nota-se que MILAN, CARDOSO \& KOLTERMANN tratam sobre infografia e TA, mas apenas MILAN trata exclusivamente. Enquanto STRACK et al, CARDOSO \& KOLTERMANN apresentam autores em comum em seus artigos, sendo o primeiro artigo de STRACK et al a continuidade do outro. Além disso, são os únicos autores desta tabela que tratam de TA, educação e infografia em um mesmo artigo, fato este que aumenta sua atenção por sinalizar para a similaridade com a pesquisa proposta por este artigo.

Por outro lado, em relação à TDAH não foi encontrado nenhum resultado específico que considerasse a ocorrência da infografia associada como tema de pesquisa (fig. 1 e quadro 2). Por isso, além do Google Acadêmico, utilizou-se outras 8 bases de dados, nas quais foram pesquisadas 19 variações dos termos "infografia + TDAH", em 3 idiomas, conforme a seguir (quadro. 2). 
Quadro 2 - Busca em base de dados pelo tema central da pesquisa

\begin{tabular}{|c|c|c|c|}
\hline \multirow{2}{*}{$\begin{array}{l}\text { Bases de dados } \\
\text { pesquisadas }\end{array}$} & \multicolumn{3}{|c|}{ Idiomas (3)/ termos pesquisados (19) } \\
\hline & Português (4) & Inglês (9) & Esp \\
\hline $\begin{array}{l}\text { (1) Springer Link } \\
\text { (2) Diretory of open } \\
\text { acess books (DOAB) } \\
\text { (3) Portal para } \\
\text { periódicos de acesso } \\
\text { (4) livre na Internet } \\
\text { (LivRe) } \\
\text { (5) Portal de } \\
\text { periódicos da Capes } \\
\text { (6) SciELO } \\
\text { (7) SciELO books } \\
\text { (8) Biblioteca Digital } \\
\text { Brasileira de Teses e } \\
\text { Dissertações (BDTD) }\end{array}$ & $\begin{array}{l}\text { (1) "Infográfico + } \\
\text { TDAH" } \\
\text { (2) "Infografia + } \\
\text { TDAH" } \\
\text { (3) "Infográfico + } \\
\text { transtorno de } \\
\text { déficit de atenção e } \\
\text { hiperatividade" } \\
\text { (4) "Infografia + } \\
\text { transtorno de } \\
\text { déficit de atenção e } \\
\text { hiperatividade" }\end{array}$ & $\begin{array}{l}\text { (5) "infographic + Attention } \\
\text { Deficit Hyperactivity Disorder" } \\
\text { (6) "infographic }+A D H D \text { " } \\
\text { (7) "infographic }+A D / H D " \\
\text { (8) "infographic + attention } \\
\text { deficit disorder" } \\
\text { (9) "infographic + DDA" } \\
\text { (10) "informational graphics + } \\
\text { ADHD" } \\
\text { "informational } \\
\text { (11) "graphics + AD/HD" } \\
\text { (12)" informational graphics + } \\
\text { attention deficit disorder } \\
\text { informational" } \\
\text { (13) "graphics + Attention } \\
\text { Deficit Hyperactivity Disorder" }\end{array}$ & 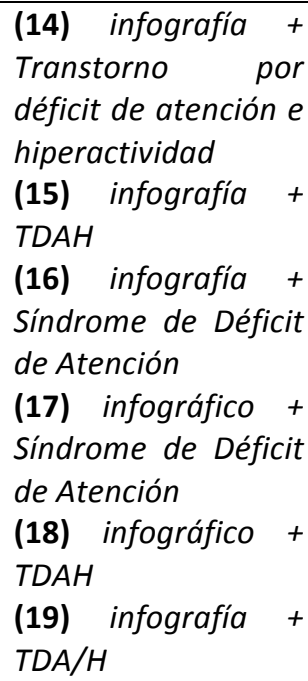 \\
\hline
\end{tabular}

Fonte: Elaborado pelos autores, com base na pesquisa realizada.

Da mesma forma, não foi encontrada nenhuma pesquisa sobre "infografia + TDAH", apenas foi encontrado o uso ilustrativo da infografia como um recurso para auxiliar a explicação de outros assuntos.

O fato de não terem sido encontradas pesquisas sobre "infografia + TDAH" leva às seguintes hipóteses: (1) não há interesse por parte dos pesquisadores em investigar a correlação "infografia+TDAH"; (2) é um tema com pesquisa incipiente; (3) ou que existem indícios de ineditismo nesta relação em específico e que há a oportunidade de investigações das mais diversas abordagens; (4) os estudos sobre infografia e educação seriam suficientemente aplicáveis de modo universal, independente de o aluno ser ou não deficiente.

Em um terceiro momento, buscou-se a relação da infografia com a educação (fig. 1). Desta vez, obteve-se sucesso em encontrar artigos que apresentassem pesquisas com este enfoque, o que garantiu suporte para dar prosseguimento a este estudo.

Neste sentido, busca-se como objetivo geral evidenciar a possibilidade de desenvolvimento de um modelo conceitual que auxilie na melhoria do acesso à educação para pessoas com TDAH, a partir do estudo da relação entre infografia, TA, educação e TDAH.

Assim, a relevância deste estudo também se concentra no fato de se poder contribuir para melhoria da educação e consequentemente da qualidade de vida de pessoas com TDAH. Além disso, há a possibilidade de despertar também a atenção de alunos não diagnosticados com TDAH e os alunos ainda não diagnosticados com TDAH, podendo o mesmo material didático ser apresentado para os alunos que apresentem TDAH e para os que não apresentem.

Considera-se ainda como um fator motivador ao estudo os números do IBGE de 2009-2010, que segundo MATTOS et al (2012) apontam que quase 1 milhão de pessoas sofrem de TDAH no Brasil e $10 \%$ da população mundial, segundo a Associação Brasileira de Déficit de Atenção (2013).

Por isso, este estudo investiga e relaciona os seguintes assuntos principais que norteiam e delimitam a pesquisa: "Infografia + TA, educação + TDAH". Sendo que, para 
isso, adota determinado método de pesquisa científica de modo sistematizado que é apresentado a seguir.

\section{DESENVOLVIMENTO DA PESQUISA}

\subsection{Procedimentos Metodológicos}

A pesquisa apresentada caracteriza-se como qualitativa, por apresentar apreciação dos dados, considerando aspectos que não tem por objetivo serem mensurados. Esta foi realizada a partir do levantamento documental, considerando as pesquisas existentes, especialmente, artigos científicos que abordem os temas aqui investigados e suas relações, mesmo que parciais.

Para isto, foi eleito o método "analítico-descritivo" caracterizando a pesquisa também como "analítico-descritiva", porque "observa, registra, correlaciona e descreve fatos ou fenômenos de uma determinada realidade sem manipulá-los" (VALETIM, 2005).

Desta forma, foram adotadas as seguintes etapas principais, que compõem a pesquisa inicial e o seu desenvolvimento:

A - pesquisa exploratória; B - especificação de critérios de seleção de artigos (termos de busca); C - seleção de artigos; D - levantamento e descrição de conceitos e ideias; $\mathrm{E}$ - interpretação e relação de variáveis; $\mathrm{F}$ - discussão qualitativa sobre os dados obtidos.

A seguir apresenta-se o embasamento teórico sobre os principais temas deste artigo. Este embasamento considera uma abordagem a respeito dos dados encontrados na revisão teórica destacando os aspectos aderentes aos temas propostos.

\subsection{Fundamentação Teórica}

Para um melhor entendimento da abordagem do estudo proposto, é necessária a realização de uma breve revisão teórica considerando os seguintes conceitos básicos envolvidos: (1) Tecnologia Assistiva, (2) Deficiência, (3) TDAH e (4) Infografia. Em um segundo momento, apresenta-se os artigos investigados e descrevem-se os principais aspectos abordados pelo conteúdo de cada um deles.

Segundo o Comitê de Ajudas Técnicas - CAT a Tecnologia Assistiva é algo amplo e de cunho social, apresentando-se como:

“...uma área do conhecimento de característica interdisciplinar, que engloba produtos, recursos, metodologias, estratégias, práticas e serviços que objetivam promover a funcionalidade, relacionada à atividade e participação de pessoas com deficiência, incapacidades ou mobilidade reduzida, visando sua: autonomia, independência, qualidade de vida e inclusão social". (CAT, 2007).

Em complemento, a este conceito, o CAT destaca que:

"A deficiência é considerada uma condição de ausência ou não funcionamento adequado de parte do corpo, a incapacidade, uma dificuldade ou impossibilidade de realizar uma ação pretendida e a desvantagem, uma privação da participação social em igualdade de direitos e condições." (Idem).

Entretanto, para o entendimento pleno destes conceitos ainda deve-se considerar também as dificuldades existentes as quais apontam que "A deficiência é complexa, dinâmica, multidimensional, e questionada." (OMS, 2012). Além das 
dicotomias existentes destes conceitos em relação à jurisprudência. Outro conceitochave para este estudo é o de Transtorno de Déficit de Atenção e Hiperatividade, o TDAH, que é entendido pela Associação Brasilera de Déficit de Atenção - ABDA como:

“...um transtorno neurobiológico, com grande participação genética (isto é, existe chances maiores de ele ser herdado), que tem início na infância e que pode persistir na vida adulta, comprometendo o funcionamento da pessoa em vários setores de sua vida, e se caracteriza por três grupos de alterações: hiperatividade, impulsividade e desatenção." (ABDA(a), p. 4, 2013).

Além disso, conforme a "Cartilha de Direito dos Portadores de TDAH: doutrina jurisprudência", desta mesma entidade, estimativas apontam que:

"o TDAH não é um simples transtorno, mas um problema grave de saúde que afeta aproximadamente $10 \%$ da população mundial caracterizada por uma combinação de dois tipos de sintomas: Desatenção e Hiperatividade - Impulsividade. O que caracteriza a deficiência, assim entendida, de acordo com o Dicionário de Língua Portuguesa, Aurélio - Ed.2010, é a falta, carência, insuficiência (física ou psíquica). Portanto, não há como deixar de considerar tal transformação grave de saúde como deficiência." (ABDA(b), p. 5, 2013).

Todavia não existe uma lei específica que se destine ao cuidado de pessoas com TDAH. Porém, tramita na Câmara dos Deputados (2014) o Projeto de Lei (PL) 7081/2010 que tem origem no PLS 402/2008 (Projeto de Lei do Senado) e dispõe sobre o diagnóstico e o tratamento da Dislexia e do Transtorno do Déficit de Atenção com Hiperatividade, exclusivamente para alunos da educação básica. Até o momento, a situação do PL encontra-se como: "Pronta para Pauta na Comissão de Finanças e Tributação (CFT)" (Idem).

Desta forma, o uso da infografia na educação de pessoas com TDAH considerando as características apresentadas - mostra-se como um recurso potencializador da percepção. Deste modo, espera-se que este recurso possa vir a contribuir com o melhor desempenho do aluno com TDAH, considerando-se a capacidade da infografia em tornar atrativo os mais diversos assuntos ou de apresentar de forma simples informações complexas, a partir da organização e estética da informação que é possibilitada pela articulação dos elementos visuais de seu design gráfico.

Neste sentido, pode-se entender infografia (fig. 2) de modo amplo, como "qualquer informação apresentada em forma de um diagrama - isto é, desenhos nos quais se mostram as relações entre diferentes partes de um conjunto ou sistema - é uma infografia". (CAIRO,2008). Por outro lado, Peltzer (1992), faz distinção e entende os gráficos menores presentes na infografia, como componentes auxiliares denominados infogramas. Nesta progressão, Ribeiro (2008) assinala o termo "infografia" como uma palavra proveniente do termo norte-americano infographic que, ao ser adotado na língua espanhola, originou os termos "infográfico" e "infografia", sendo que a primeira palavra é uma forma adjetivada para se fazer referência à segunda. (Idem).

De modo geral, diversos autores indicam qual seria o termo mais apropriado. Porém, no Brasil, as palavras "infografia" e "infográfico" são empregadas usualmente como sinônimos, nas mais diversas situações, por infografistas de renome como Mario Kanno, que trabalha para o jornal Folha de São Paulo e Luiz Iria que é Editor de Infografia da Revista Superinteressante. 


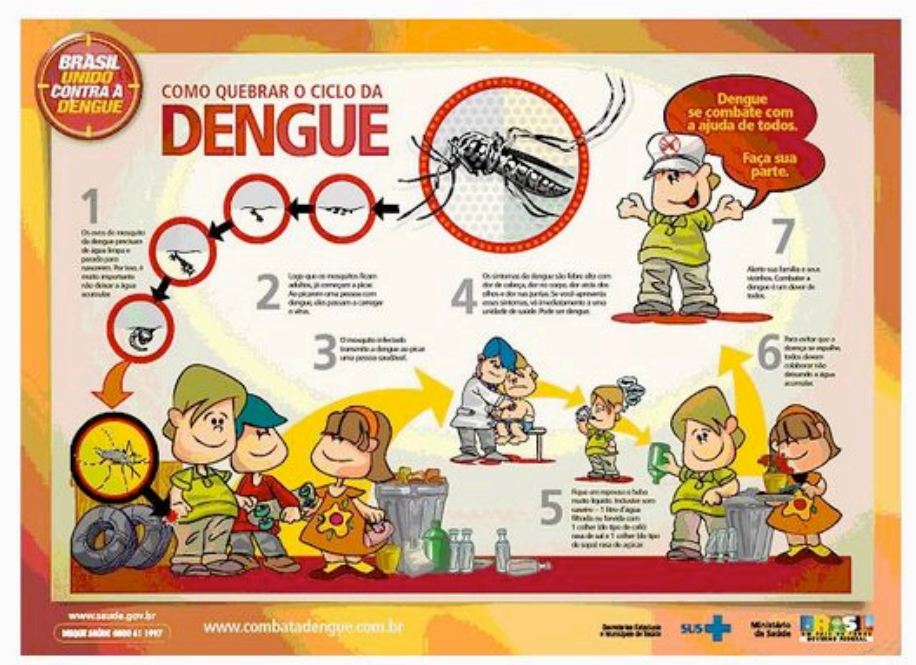

Figura 2: Infografia da Campanha Nacional contra a Dengue. Fonte: BRASIL (2014).

Atualmente, não há dúvidas sobre os benefícios que a infografia pode trazer para a educação ou para a melhor compreensão dos dados de uma determinada informação. Contudo, ao pesquisar-se sobre este tema foram encontrados apenas 4 artigos e 1 tese que relacionam "infografia e educação" como conteúdo de investigação conforme apresentado a seguir (quadro 3).

Quadro 3 - Relação do material investigado sobre infografia e educação

\begin{tabular}{|l|l|l|}
\hline ID & Autor (es) & Título (Tipo de material) \\
\hline (A) & ALVAREZ, 2012 & $\begin{array}{l}\text { A infografia na educação: contribuições para o pensar crítico e } \\
\text { criativo (tese) }\end{array}$ \\
\hline (B) & BOTTENTUIT et al, 2011 & O infográfico e as suas potencialidades educacionais (artigo) \\
\hline (C) & PESSOA \& MAIA, 2012 & $\begin{array}{l}\text { A infografia como recurso didático na educação a distância } \\
\text { (artigo) }\end{array}$ \\
\hline (D) & PEÇAIBES \& MEDEIROS, 2010 & $\begin{array}{l}\text { O dinamismo das apresentações visuais: infográficos aplicados } \\
\text { à educação (artigo) }\end{array}$ \\
\hline (E) & STRACK et al, 2011 & $\begin{array}{l}\text { A infografia como recurso pedagógico no ensino de } \\
\text { acessibilidade em ambientes culturais (artigo) }\end{array}$ \\
\hline
\end{tabular}

Fonte: Elaborado pelos autores, com base na pesquisa realizada.

O conteúdo da tese investigada (A) apresenta entre outras coisas análises de infografias existentes e sugere a estratégia de ensino de construção de releituras de infografias pelos alunos, objetivando o desenvolvimento do pensamento crítico de modo que transcenda ao senso comum (ALVAREZ, 2012).

Outra pesquisa (B) apresenta a infografia e sua potencialidades educacionais, onde o autor, Bottentuit (et al, 2011), aponta que isto foi possível "a partir da revisão de literatura e manuseio de infográficos". As possibilidades identificadas são as seguintes: (1) os alunos podem acompanhar passo-a-passo um processo, fato ou acontecimento histórico; (2) a riqueza de imagens e esquemas facilita a memorização por parte dos alunos; (3) possibilita a alfabetização visual visto que muitas das vezes os alunos observam a imagem de maneira geral sem perceber aspectos importantes que só são perceptíveis com uma maior atenção a determinadas áreas de um infográfico; (4) o aluno tem um maior controle sobre o recurso visual e a sua aprendizagem, pois poderá explorar e revisar quantas vezes desejar cada fase do processo apresentado no infográfico; (5) o infográfico poderá constituir-se num poderoso atrativo para veiculação da informação em ambientes e plataformas de ensino e aprendizagem; (6) 
as imagens chamam a atenção dos alunos e o processo de observação dos infográficos poderá desenvolver as habilidades cognitivas de interpretação, análise e síntese; (7) os alunos recordam mais facilmente de imagens e pequenos fragmentos de textos face à grande quantidade de textos sem o uso de esquemas ou imagens; (8) o aluno através do infográfico poderá realizar uma navegação não linear sobre o conteúdo e desta forma realizar novas descobertas; (9) o professor poderá combinar recursos multimídia durante as suas aulas com o intuito de melhorar o processo de ensino e aprendizagem dos alunos; (10) permitem a visualização de processos muito lentos (o desabrochar de uma flor) ou muito rápidos (a transmissão do som); (11) o aluno poderá manipular o infográfico inúmeras vezes até que consiga realizar a compreensão completa do processo; (12) o aluno poderá utilizar o infográfico como uma fonte de informação, um recurso didático, um recurso para exploração visual e ainda para resolução de problemas ou questões elaboradas pelo professor.

Outro artigo (C) investiga em que medida e por quais razões a infografia deve ser utilizada como meio complementar de ensino, apresentando algumas possibilidades de uso considerando que: "Não cabe ao docente ou ao produtor de conteúdo saber realizar tecnicamente um infográfico, mas é de sua responsabilidade entender e compreender o que as tecnologias de informação oferecem como recurso educacional." (PESSOA \& MAIA, 2012).

Uma breve análise do terceiro artigo (D) identifica que seu conteúdo sugere que deva existir uma disciplina específica sobre infografia desde as séries iniciais visando contribuir com o desenvolvimento do potencial criativo do indivíduo. (PEÇAIBES \& MEDEIROS, 2010).

A partir da leitura do quarto artigo (E) identificou-se tema próximo ao proposto neste artigo à medida que relaciona "infografia, ensino e acessibilidade", enquanto esta proposta investiga a relação "infografia, TA, educação e TDAH". O artigo analisado apresenta revisão teórica sobre infografia e o desenvolvimento de infografias onde "além de ser produto de projeto de extensão, também é objeto de pesquisa e estão servindo como material de apoio nas disciplinas de Projeto Integrado I". (STRACK, 2011). Outro aspecto que destaca-se no artigo é o modo pontual como são identificado os elementos visuais envolvidos e seus objetivos, além da clareza do método empregado para geração das infografias.

Outro artigo que destaca-se por abordar os temas "infografia, educação e TA" é o artigo de CARDOSO \& KOLTERMANN (2010) como já identificado anteriormente (fig. 02). Este apresenta uma abordagem que depois foi continuada em outra publicação por STRACK et al (2011), como já mencionado.

Neste sentido, cabe a seguir a ampliação da análise e a discussão a respeito das possibilidades de contribuição do conteúdo identificado, a partir desta breve revisão teórica em relação aos temas envolvidos neste artigo, suas correlações e eventuais desdobramentos.

\subsection{As relações entre infografia, TA, educação e TDAH}

Neste tópico são apresentados, organizados e analisados os dados obtidos, de modo a promover sua interpretação e relacionar as variáveis envolvidas, a partir de discussão qualitativa sobre os mesmos, caracterizando o estudo como hipotéticodedutivo (POPPER, 1975), que consiste na dedução das conseqüências na forma de proposições passíveis de teste, incluindo a observação. Para isto, são consideradas as 
categorizações de busca apresentadas na pesquisa exploratória para organização das ideias descobertas na revisão teórica dos artigos por tema: (1) "infografia+TA" e (2) "infografia+educação". Além das relações não encontradas na pesquisa exploratória como (3) "infografia + DTAH", conforme aqui apresentado. A partir disto, busca, por fim, relacionar (4) "infografia + TA, educação + TDAH". (fig. 3).

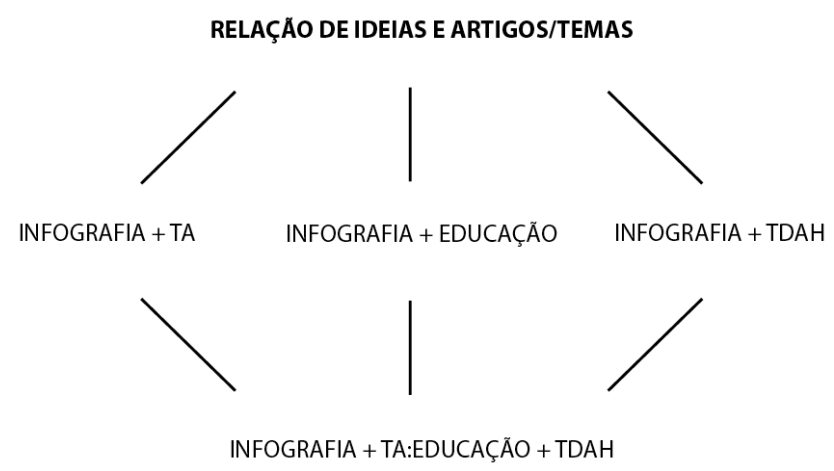

Figura 3: Relação de ideias e artigos. Fonte: Elaborado pelos autores, com base na pesquisa realizada.

Neste sentido, visando alcançar a ideia de, no mínimo, evidenciar possibilidade de geração de um modelo conceitual que tenha por objetivo a melhoria do aprendizado de pessoas com transtorno de déficit de atenção e hiperatividade (TDAH). Indicando para isso, o recurso tecnológico da infografia, amplamente utilizado em jornais e revistas para melhor explicar determinado assunto de modo atrativo.

Sobre a relação entre (1) "infografia + TA", dentre a amostra de dados coletadas, pode-se afirmar que foi encontrada proposta bastante inusitada, ampliando o conceito de infografia para possibilidade de materiais tridimensionais e táteis, que independente do seu objetivo original, apresenta-se também como uma possibilidade de outra forma de alunos com TDAH interagirem com a informação, diferente da forma proposta inicialmente por este artigo - que era a possibilidade de inserção e construção de infografias estáticas e bidimensionais nas apresentações visuais, direcionadas aos alunos com TDAH. A relação investigada entre (2) "infografia+educação", embora não tenha apresentado relação com o tema TDAH, nas discussões e recomendações gerais quanto às possibilidades de uso da infografia na educação, mostrou-se de grande valia, pois identificou alguns aspectos que também podem vir a ser trabalhados com alunos com TDAH, a partir de adaptações. Dentre estes aspectos destacam-se: (A) a estratégia de ensino de construção de infografia a partir de releituras para o desenvolvimento do pensamento crítico do aluno; (B) a identificação de possibilidades educacionais do uso da infografia; (C) caracterização da humildade da infografia como um meio complementar de ensino; (D) a relevância da infografia enquanto contribuição para o desenvolvimento do potencial criativo do indivíduo; (E) que uma mesma infografia pode apresentar-se com funções de objeto de pesquisa, produto, material didático e ser ilustrativa.

Desta forma, estes aspectos também são considerados como relevantes e fazem parte do modelo conceitual aqui proposto. Embora em relação ao tema (3) "infografia + TDAH", não tenha sido encontrado nenhum material específico, foram encontrados 2 artigos que relacionam infografia, tecnologia assistiva, educação e deficiência visual. E a partir destes foi possível identificar que podem existir outros estudos correlatos à proposta deste artigo, contudo contemplando outros tipos de deficiência e possivelmente sobre TDAH. Mas, especificamente sobre infografia, em 
sua concepção, esta deveria considerar preferencialmente todas as características da TDAH. Contudo, sabe-se que a TDAH pode apresentar diversos sintomas e que estes podem inclusive ser dicotômicos. E que isto certamente impossibilita adaptar a infografia para cada variante de TDAH. Por exemplo, uma infografia com determinadas cores e formas destinada para pessoas desatentas, tímidas e calmas pode não funcionar bem com pessoas hiperativas ou impulsivas e vice-versa.

Logo, deve-se considerar detectar os tipos de TDAH presentes nos alunos e como solução poderia-se desenvolver e apresentar simultaneamente no mínimo 2 versões das apresentações visuais (slides), dividindo o espaço da tela em proporções iguais como uma medida inclusiva, independente da quantidade de alunos, contudo, isto poderia acarretar o inverso do pretendido por não ser uma solução estética coerente. Portanto, sugere-se como solução intercalar elementos e estratégias que contemplem aos alunos desatentos e aos hiperativos em uma mesma infografia ou apresentação. Por exemplo, usar infografias estáticas e animadas. Além disso, há a indicação de algumas possibilidades para a geração do modelo conceitual em questão, que disporia, entre outras coisas, de recomendações a respeito de tipologias de infográficos mais adequados para determinados tipos de informação.

Para concepção deste modelo além do conhecimento específico em infografia, deve-se considerar as peculiaridades do conhecimento da disciplina e certamente a diversidade cultural e o tipo e grau de deficiência das pessoas envolvidas. Nesta progressão pode-se identificar, na análise de MATTOS et al (2012) a partir de dados do IBGE, que em 2009-2010 existem estimativas bastante conservadoras para o TDAH na população, e que estas apontam que pelo menos 924.732 pessoas são afetadas pelo TDAH no Brasil, estando divididas nas faixas etárias entre 5 e 19 anos (442.143 pessoas) e entre 20 a 59 anos (482.589 pessoas).

Já para a construção de infografias a serem utilizadas em materiais didáticos constatou-se que não há a necessidade de geração de um software específico ou do domínio pleno em design gráfico pelo professor. Isto ocorre em razão da existência de aplicativos que possibilitam acessibilidade aos professores que não sejam da área do design gráfico. É claro que se o professor que utilizar estas ferramentas para composição de infografias possuir conhecimento sobre aspectos estéticos, seja relacionado a artes visuais ou comunicação visual, isto contribuirá para a otimização e composição deste processo. Certamente isto contribuirá também para a visualidade dos dados em questão, caso aplique seu conhecimento na área gráfico-visual, sendo válido tanto para composição de uma apresentação de slides em "Power Point" ou "Prezi" como para construção de uma infografia.

Dentre os aplicativos freeware destaca-se o Easel.ly que proporciona uso intuitivo e permite a construção de infografias a partir de temas customizáveis e upload de imagens. Enquanto o site Visual.ly disponibiliza alguns templates gratuitamente, também customizáveis.

Logo, mesmo que alguns autores apontem que a construção da infografia e a necessidade de domínio técnico não sejam de responsabilidade do professor, este pode construir e possui recursos para tal, o que pode acelerar o processo, gerar a obtenção de resultados e a garantia do projeto ficar de acordo com o idealizado.

Portanto, retomando a abordagem das correlações de investigação proposta, pode-se considerar que o tema (4) "infografia + TA, educação + TDAH", depende do entendimento isolado e pleno de cada subtema para que exista uma aplicação efetiva 
e de modo apropriado, considerando as peculiaridades da TDAH. Além disso, devem ser consideradas todas as recomendações aqui apresentadas, seja para composição de material didático, de adequação ou ampliação do modelo conceitual evidenciado.

\section{CONSIDERAÇÕES FINAIS}

O presente estudo evidenciou a possibilidade de desenvolvimento de um modelo conceitual que auxilie na melhoria do acesso à educação para pessoas com TDAH, a partir do estudo da relação entre infografia, TA, educação e TDAH. Isto indicou a necessidade de ampliação das pesquisas nesta área, por evidências como (1) a ausência de material específico, (2) a gravidade envolvida e (3) suas estatísticas.

Além disso, as pesquisas apresentadas para construção do corpus teórico deste artigo também contribuíram para reforçar a relevância da investigação do tema proposto. Quanto à metodologia empregada, esta possibilitou coletar, selecionar, organizar e analisar os dados encontrados de modo pertinente ao seu conteúdo, ou seja, de forma analítico-descritiva permitindo assim a correlação dos temas investigados articulado em conjunto com o pensamento dedutivo e contemplando todas as etapas previstas. Em relação às hipóteses apresentadas na introdução deste artigo, pode-se afirmar que: (1) há interesse dos pesquisadores em investigar a correlação entre infografia, educação, tecnologia assistiva e deficiências; (2) a pesquisa da correlação entre infografia e TDAH apresenta traços de incipiência; (3) possivelmente a correlação entre os temas deste artigo não seja inédita, tendo em vista a existência de pesquisas que correlacionam as mais diversas deficiências com infografia; (4) os estudos sobre infografia e educação podem ser aplicados, independente da pessoa ser ou não deficiente, contudo devem ser adaptados as deficiências envolvidas.

Considerando-se esta discussão proposta, pode-se acreditar que independente da classificação como estratégia ou produto, e de sua aplicação, prototipação ou testagem, o uso da infografia pode auxiliar na ampliação das possibilidades de percepção para pessoas com TDAH. Consequentemente, há a possibilidade de melhoria no aprendizado, caso sua aplicação ocorra de modo adequado, estratégico e pontual, evitando que o uso da infografia se torne um recurso enfadonho ou banal e que não desperte mais a atenção do aluno com TDAH. Como recomendações para estudos futuro sugere-se: (1) testagem e avaliação das ferramentas de composição de infografias; (2) elaboração de aula com infografias e testagem com pessoas com TDAH; (3) investigar sobre o potencial das infografias estáticas, animadas e interativas para pessoas com TDAH; (4) entrevistar ou fazer artigo em conjunto com profissionais da área da saúde, especialmente, Neurociência; (5) investigar como Infografia e Realidade Aumentada poderiam ser trabalhadas visando o acesso à educação e o TDAH.

Além disso, em relação aos conhecimentos levantados e gerados, pode-se afirmar que, as pesquisas consultadas e este artigo, embora se apresentem no nível das ideias, podem ser aplicados de modo experimental à prática pedagógica. E que, seus possíveis relatos, caso sejam configurados em artigos científicos, certamente enriquecerão ainda mais os estudos em Tecnologia Assistiva. Estes também contribuirão para o enaltecimento da relevância do estudo em TA, considerando ainda que esta também se dá pelo fato de que a qualquer momento da vida, qualquer pessoa pode vir a possuir algum tipo limitação física ou mental, mesmo que temporária, configurando-se como uma deficiência. 


\section{REFERÊNCIAS}

ABDA(a) - Associação Brasileira de Déficit de Atenção. Cartilha ABDA. Disponível em: <http://www.tdah.org.br/images/stories/site/pdf/cartilha_abda.pdf> Acesso em: 03 abr. 2014.

(b). Direito dos Portadores de TDAH: doutrina - jurisprudência. Disponível em: $<$ http://www.tdah.org.br/images/stories/site/pdf/Cartilha-Direito-dos-Portadores-deTDAH.pdf> Acesso em: 03 abr. 2014.

ALVAREZ, A. A infografia na educação: contribuições para o pensar crítico e criativo. 2012. 313f. Doutorado (Doutorado em Educação). Departamento de Educação, Pontifícia Universidade Católica de São Paulo, São Paulo, 2012.

BOTTENTUIT, J. et al. $\mathbf{O}$ infográfico e as suas potencialidades educacionais. IV Encontro Nacional de Hipertexto e Tecnologias Educacionais. Universidade de Sorocaba, São Paulo, 2011.

BRASIL. Infografia da campanha nacional de combate à dengue. Disponível em: <http://www.combatadengue.com.br> Acesso em: 08 abr. 2014.

CAIRO, A. Infografia 2.0. Madrid: Alamut, 2008.

CÂMARA DOS DEPUTADOS. Projeto de Lei 7081/2010. Disponível em: $<$ http://www.camara.gov.br/proposicoesWeb/fichadetramitacao idProposicao $=47240$ 4> Acesso em: 08 set. 2014.

CARDOSO, E.; KOLTERMANN, T. Recursos para acessibilidade em sistemas de comunicação para usuários com deficiência. Revista Design e Tecnologia - UFRGS. v. 2, $n^{\circ} 1$, p. $8-21,2010$.

CAT - Comitê de Ajudas Técnicas. Relatório Anual 2007. Disponível em: < http://www.acessobrasil.org.br/CMS08/seo-publicacoes-6.htm> Acesso em: 08 abr. 2014.

MATTOS, P. et al. O TDAH é subtratado no Brasil. Revista Brasileira de Psiquiatria, v. 34, $n^{\circ}$ 4, p. 513-516, 2012.

MILAN, L. Maquetes táteis: infográficos tridimensionais para a orientação espacial de deficientes visuais. Revista Parc - UNICAMP. v. 1, n² 2, p. 1-26, 2008.

MURPHY, G. D. Post-PC devices: A summary of early iPad technology adoption in tertiary environments. E-Journal of Business Education \& Scholarship of Teaching, $v$. 5, n' 1, p. 18-32, 2011.

OMS. Relatório Mundial sobre a Deficiência. São Paulo: SEDPcD, 2012.

PESSOA, A.; MAIA, G. A infografia como recurso didático na educação a distância. Revista Temática - UFPB. Ano VIII, $\mathrm{n}^{\circ}$ 5, 2012.

PEÇAIBES, M.; MEDEIROS, L. O dinamismo das apresentações visuais: infográficos aplicados à educação. $9^{\circ}$ Congresso Brasileiro de Pesquisa e Desenvolvimento em Design. Anhembi Morumbi, Anais, p. 2938-2941, São Paulo: Blücher, 2010.

PELTZER, G. Jornalismo Iconográfico. Lisboa: Planeta, 1992.

POPPER, K. La ciência normal y SUS peligos. In: Lakatos y Musgrave. La crítica y EI desarrolo Del conocimento. Barcelona: Ediciones Grijalbo, 1975.

RIBEIRO, S. Infografia de imprensa. Coimbra: Minerva Coimbra, 2008.

STRACK, V. et al. A infografia como recurso pedagógico no ensino de acessibilidade em ambientes culturais. $5^{\circ}$ Congresso Brasileiro de Extensão Universitária. Universidade Federal do Rio Grande do Sul, Porto Alegre, 2011.

VALENTIM, M. (Org.). Métodos qualitativos de pesquisa em Ciência da Informação. São Paulo: Polis, 2005. 